Anuario del Instituto de Historia Argentina, junio 2018, vol. 18, n ${ }^{\circ}$, e066. ISSN 2314-257X Universidad Nacional de La Plata

Facultad de Humanidades y Ciencias de la Educación

Centro de Historia Argentina y Americana

\title{
Tierras, armas y política en la frontera sur bonaerense durante la década de 1850. Los “indios amigos”, Maicá y Villa Fidelidad
}

\section{Lanteri, Sol}

CONICET-Universidad de Buenos Aires, Argentina

sol_lanteri@conicet.gov.ar

\section{Pedrotta, Victoria}

Universidad Maimónides-CONICET, Argentina Universidad Nacional de La Plata -

Facultad de Ciencias Naturales y Museo, Argentina

vpedrotta@conicet.gov.ar

Cita sugerida: Lanteri, S. y Pedrotta, V.(2018). Tierras, armas y política en la frontera sur bonaerense durante la década de 1850. Los "indios amigos", Maicá y Villa Fidelidad Anuario del Instituto de Historia Argentina, 18 (1), e066. https://doi.org/10.24215/2314-257Xe066

Recibido: 01 Agosto 2017 - Aceptado: 02 Febrero 2018 - Publicado: 28 de junio de 2018

(i) (1) Esta obra está bajo licencia Creative Commons Atribución-NoComercial-CompartirIgual 4.0 Internacional

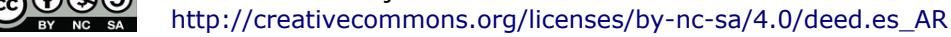




\title{
Tierras, armas y política en la frontera sur bonaerense durante la década de 1850. Los “indios amigos", Maicá y Villa Fidelidad
}

Lands, arms and politics in the Buenos Aires southern frontier during the decade of 1850. "Friendly Indians", Maicá and Villa Fidelidad

\author{
Sol Lanteri \\ CONICET-Universidad de Buenos Aires, Argentina \\ sol_lanteri@conicet.gov.ar \\ Victoria Pedrotta \\ Universidad Maimónides-CONICET, Argentina \\ Universidad Nacional de La Plata-Facultad de Ciencias \\ Naturales y Museo, Argentina \\ vpedrotta@conicet.gov.ar
}

\section{RESUMEN:}

El objetivo del trabajo es indagar el origen y características del emplazamiento azuleño de "Villa Fidelidad" y las tierras de los "indios amigos", atendiendo al contexto de la expansión criolla y oficial en la frontera sur, la interacción con la sociedad indígena, así como las disputas políticas e interétnicas y las reconfiguraciones territoriales a partir de Caseros. La metodología empleada contrasta documentación editada e inédita triangulada con fuentes secundarias. Los principales resultados refieren a la singularidad del reconocimiento de tierras y la entrega de solares efectuada en 1856, concluyendo que ambas deben entenderse en correlato directo de esa crítica coyuntura como una estrategia del Estado de Buenos Aires para pacificar la frontera y, en el caso de Maicá, como una contraprestación de bienes por servicios públicos en compensación de su apoyo militar.

Palabras Clave: Frontera Sur de Buenos Aires, Década de 1850, Territorialidad de “indios amigos”, Maicá, "Villa Fidelidad”.

\section{Abstract:}

The aim of this work is to examine the origin and characteristics of "Villa Fidelidad" Azul's emplacement and the friendly Indians ' lands, in the frame of the creole and official expansion in the southern frontier, the interaction with the indigenous society, the political and interethnic disputes and the territorial reconfigurations since Caseros. The methodology employed contrasts published and unpublished documentation with secondary sources. The main results refer to the singularity of land recognition and the delivery of urban plots in 1856, concluding that both must be understood in direct relation to that critical conjuncture as a strategy carried out by the Buenos Aires state in order to appease the frontier, and, in the case of Maicá, as a counterpart of goods for public services in return for military support.

KEYWORDS: Buenos Aires southern frontier, Decade of 1850, Friendly Indians' territoriality, Maicá , "Villa Fidelidad".

\section{INTRODUCCIÓN}

Villa Fidelidad no logró ninguno de los propósitos civilizadores que concibiera su generoso fundador. Apartó del malón algunas huestes y contribuyó en alguna medida, no muy grande, al poder militar del gobierno, pero no alcanzó, como conjunto humano, otra significación que la de una simple toldería suburbana, transplantada de la inmensidad de la llanura al arrabal de un pueblo, tan miserable y salvaje como todas sus congéneres, como aquellas tolderías ranquelinas que describe el General Mansilla en el más divulgado de sus libros (Ronco, 1946, p. 20; énfasis nuestro).

Así describía, desde la perspectiva dicotómica tradicional de civilización vs. barbarie, el historiador local Bartolomé Ronco, casi un siglo después de su fundación a "Villa Fidelidad", que todavía hoy llamativamente es un barrio periférico de la ciudad de Azul, en el centro-sur de la provincia de Buenos Aires. Este emplazamiento urbano, que fue establecido en 1856 por el general Manuel Escalada y agrupó principalmente a los miembros de la agrupación del cacique Maicá al oeste del pueblo de Azul, constituye un caso singular 
en el marco de otros asentamientos de "indios amigos" en la frontera bonaerense por su continuidad en la mediana-larga duración y por otras cuestiones que se desarrollan en este trabajo.

En los últimos años, algunos estudios han analizado el tema de las tierras de los llamados "indios amigos" en distintos sectores de la actual provincia de Buenos Aires durante la segunda mitad del siglo XIX, observando los cambios y las continuidades de la política del "negocio pacífico" cimentada en el gobierno de Juan Manuel de Rosas (1829-52). Estas valiosas contribuciones, realizadas principalmente desde la Antropología Histórica, han analizado los tratados diplomáticos, las alianzas políticas, la incorporación de nuevos grupos "amigos" y la reorganización de los antiguos, las relaciones intertribales e interétnicas con los indígenas de "tierra adentro", su participación en el faccionalismo político, así como las características, gestores y receptores de las concesiones territoriales, entre otras cuestiones (Barbuto, 2014; Literas y Babuto, 2014; Literas, 2015, 2016; de Jong, 2007, 2015). Los trabajos citados focalizan en el período posterior a la década de 1860, una vez unificado el Estado hasta el fin de la frontera, a la vez que refieren especialmente a los sectores del oeste o norte y, en menor medida, al sur provincial (Martinelli y Acosta, 2016). Se trata de abordajes efectuados con perspectivas, interrogantes, objetivos y marcos cronológicos diferentes a los planteados aquí.

Este trabajo forma parte tanto de investigaciones individuales como de un proyecto mayor sobre la tierra pública y los derechos de propiedad de campos, pueblos, ejidos y tierras indígenas en la frontera sur bonaerense durante la segunda mitad del siglo XIX, desde una perspectiva interdisciplinar que integra a la Historia, la Arqueología Histórica y la Antropología Social ${ }^{1}$. En el marco del estudio sistemático de Villa Fidelidad, que registra antecedentes preliminares (de Jong, Lanteri, Pedrotta \& Ratto, 2009; Lanteri, Ratto, de Jong \& Pedrotta, 2011), nos proponemos indagar el origen y las características de este singular caso, para cuya comprensión tomamos como ejes el contexto de la expansión criolla y oficial en la frontera sur, la interacción con la sociedad indígena, así como las disputas políticas e interétnicas y las reconfiguraciones territoriales a partir del período abierto con Caseros y el sitio de Lagos, que como es sabido, se encuentra en el nudo del interés y en proceso de revisión historiográfica desde hace varios años ${ }^{2}$.

Como puntos de partida e indagación nos preguntamos cuáles fueron las razones del establecimiento de esta "toldería suburbana" en un pueblo nodal como fue Azul en el centro-sur bonaerense, por qué aglutinó inicialmente a la parcialidad del cacique Maicá y en un año tan temprano como 1856 y cuáles fueron los rasgos distintivos principales del emplazamiento. Asimismo, contemplamos modalidades diferentes y concomitantes de acceso a la tierra de otros grupos de "indios amigos" en la misma zona de la frontera austral. Nuestra hipótesis general es que para entender el caso se debe hacer hincapié en la interconexión entre armas, tierras y política en la frontera, dentro de una coyuntura particularmente convulsa de la historia provincial e institucional de la república, como fue la década de 1850. Asimismo, consideramos que el intercambio de bienes (tierras) por servicios públicos (auxilio armado) fue una variable central y registró antecedentes significativos en la zona con respecto a otros sectores socioétnicos, que también fueron singulares en el marco provincial (ver Lanteri, 2011 y 2017).

Es dable recordar que, si bien el período abierto por el proceso de Revolución y Guerra en Buenos Aires y el Río de la Plata generó décadas convulsas ${ }^{3}$, la coyuntura abierta a la caída de Rosas se caracterizó por "conflictos de mayor envergadura y larga duración, como el que enfrentó a la Confederación y el Estado de Buenos Aires en la década de 1850" (Míguez, 2010, p. 91). De hecho, el Estado de Buenos Aires, escindido de la Confederación Argentina desde junio de 1853 a 1861, tuvo dos grandes frentes de conflicto: la seguridad de la frontera y una larga disputa armada con la Confederación. Estos frentes eventualmente se conjugaron en las alianzas del cacique Calfucurá y Justo José de Urquiza (Ratto, 2012), y en las ofensivas armadas regulares de distinta envergadura -batallas, enfrentamientos, escaramuzas, etc.-, que presentaron un gran dinamismo y volatilidad en las complejas alianzas criollas, indígenas y con las autoridades locales, de cara a los enfrentamientos políticos y militares para uno y otro bando. Además, si seguimos a Míguez (2010), se debe considerar que la importancia de la estructura caudillesca y la trama de obediencias y lealtades interpersonales fue recurrente hasta la década de 1870, cuando la estructura del Estado liberal estaba más consolidada; hasta 
entonces, el poder en la frontera estaba basado más en una red clientelar-que vinculaba indígenas y cristianos, autoridades civiles y militares, y demás agentes sociales- que en la asignación de funciones administrativas propias de un Estado moderno.

Sobre la base de estas consideraciones, en las páginas siguientes pasaremos revista, en primer lugar, a la trayectoria y el servicio armado del grupo liderado por Maicá, para luego detenernos en la relevancia de la tierra, tanto en el levantamiento armado de la tribu de los caciques Catriel y Cachul de 1855, como en la gestación de las paces del año siguiente. Seguidamente, analizaremos el lugar de Maicá en la trama de relaciones con las autoridades políticas y militares y las características de Villa Fidelidad en relación a otros predios que fueron otorgados a distintos caciques y tribus 4 “amigas" en la frontera.

\section{Trayectoria y SERVicio ARMADo DE MAICÁ}

Desde la década de 1820 aparece documentada la actuación de la parcialidad indígena al mando de Maicá, junto con otros caciques locales, en relación con los enfrentamientos armados y las negociaciones pacíficas que tuvieron lugar los años previos y posteriores a la fundación del fuerte Independencia en 1823, y la fortaleza Protectora Argentina un lustro después (Hux, 1993; Levaggi, 2000; Crivelli, 2004). Sin duda estos hechos, en conjunto con la intensificación del flujo migratorio de tribus procedentes de la Araucanía, revistieron una importancia crucial dentro de las estrategias de avance de la frontera hacia las tierras indígenas, y tuvieron fuerte impacto sobre la organización política, económica y territorial de los grupos nativos que entonces habitaban las sierras de Tandilia, Ventania y las llanuras adyacentes. En este contexto, los caciques Maicá y Pety estaban instalados hacia 1830 en la zona del arroyo Sauce Corto, donde fueron atacados y vencidos por las tropas al mando de Manuel Delgado y Narciso del Valle (Crivelli, 2004). La derrota de los lanceros indígenas y el cautiverio de sus familias determinaron que aquellos optaran por acordar las paces iniciando así una larga y sostenida relación de apoyo militar a las fuerzas criollas. Conforme relata el sargento mayor Juan Cornell (1995 [1864], p. 46): "Peti y Maicá ofrecieron la paz, por sacar sus familias y han tenido lealtad después de esto" y destaca que el propio Maicá le había corroborado tales sucesos. Es probable que estas mismas circunstancias hayan incidido también en la participación de los caciques "Maycá" y "Antuén", al mando de unos cien lanceros, en la expedición punitiva al Río Colorado de 1833-1834 que encabezó Juan Manuel de Rosas, a quien prestaron apoyo militar durante su ofensiva contra diversos grupos considerados hostiles. Según las fuentes consultadas, este es el primer antecedente sobre la participación de los lanceros de Maicá como auxiliares armados del gobierno (AGN, Sala X, 27-5-6, en Hux, 1993, p. 129).

Tiempo después, entrada la década de 1840, se produjo la instalación del grupo liderado por Maicá en la zona de Azul y Tapalqué, dentro del marco de la política indígena conocida como el "negocio pacífico". Esta peculiar trama de relaciones interétnicas -hábil, efectiva y personalmente articulada por Rosas-, que permitió la expansión de la frontera sur bonaerense, la creación de un sistema defensivo y el poblamiento criollo de nuevas tierras, tuvo como actores principales a los caciques Juan Catriel y Juan Manuel Cachul en aquella zona, y a Venancio Coñuepán en Bahía Blanca (Ratto, 2003, 2015; Lanteri, 2011). Los nombrados fueron destinatarios privilegiados de la política rosista y a comienzos de la década de 1830 se radicaron en determinados sectores de la frontera sur que habían sido acordados con el gobernador, lo que puso en marcha una aceitada contraprestación de bienes y servicios; pero el elenco de caciques que formó parte del "negocio pacífico" fue mayor, incluía a jefes de diferente jerarquía, y varió a lo largo del tiempo. En efecto, en las "Cuentas de proveedores de efectos suplidos para racionar a los indios amigos" de 1846 y 1848 , que conserva el archivo histórico de Azul, constan entregas de raciones comestibles al grupo de Maicá, junto con otros jefes y capitanejos, entre los que se encuentran los ya mencionados Juan Catriel y Cachul, además de Calfucurá, Calfiao, Pety, Guaquilaf, Epulef, etc. ${ }^{5}$

Como ha sido señalado (Ratto, 2015, p. 28-29), el apoyo militar que prestaban varias agrupaciones de "indios amigos" fue cambiando gradualmente durante el gobierno de Rosas: de intervenir esporádicamente 
en ocasión de expediciones punitivas o prestar apoyos puntuales (como chasques, baqueanos, etc.) pasaron a convertirse en milicias auxiliares del ejército provincial que debían participar en todas las acciones bélicas que enfrentara el ejército rosista, incluso en "la represión de conflictos internos criollos" 6 . En el marco de esta militarización general de la frontera, acentuada a partir de la década de 1840, en Azul se creó un piquete de "indios amigos voluntarios de los que viven en el punto para ser alistados como la milicia" en 1845 (Ratto, 2015 , p. 44) ${ }^{7}$. Una muestra emblemática de esto fueron los lanceros al mando del cacique Maicá, que entonces revistaban 45 personas entre capitanes y soldados, y se trasladaron en enero de 1852 desde Tapalqué al campamento de Santos Lugares, unidos al ejército que Rosas concentró allí de cara, nada menos, que a la batalla de Caseros (Lanteri, 2011, p. 299). Pocos meses después, las lanzas de Maicá intervinieron, junto con otros grupos nativos, en los enfrentamientos vinculados al levantamiento de la campaña bonaerense liderado por el coronel Hilario Lagos a fines de 1852. Las fuerzas indígenas de Azul y Tapalqué se mantuvieron leales a Pedro Rosas y Belgrano, lucharon en defensa de Buenos Aires durante el sitio de la misma y, luego de la batalla de San Gregorio, ayudaron a apaciguar a los distintos grupos indígenas que habían "maloneado" por su cuenta en las estancias, colaborando con la devolución de ganado robado. Esto último quedó claramente expresado por Olmos, quien afirmaba que "el cacique Catriel, Yancatul, Calfiaho, Puiti y Mayca son los que estan entregando las haciendas, que he dicho a U. [Eugenio Bustos] antes, y estan trabajando de acuerdo conmigo para aquietar a los demas indios, y persuadirlos que entreguen las haciendas" 8 .

Con la gobernación de Pastor Obligado se inició un ciclo de enorme conflictividad interétnica y recurrentes enfrentamientos armados de diversa magnitud en toda la frontera bonaerense como consecuencia del cambio de la política indígena mantenida hasta ese momento por otra, que comprendía una drástica disminución de las raciones que recibían los "indios amigos", la reorganización de las fuerzas y la reestructuración administrativa de las comandancias de frontera, el reemplazo de buena parte de las autoridades fronterizas y la imposición del avance territorial sobre las tierras indígenas. En la región centrosur, el intento de trasladar el Cantón de Tapalqué hacia las nacientes del arroyo homónimo sin el acuerdo de los caciques locales tuvo como correlato la sublevación masiva de las tribus de Catriel y Cachul, quienes se unieron a la confederación liderada por Calfucurá y protagonizaron devastadores ataques a las poblaciones criollas (Lanteri y Pedrotta, 2012). En una primera instancia el gobierno trató de controlar la situación manu militari, para lo cual contó con el apoyo de Maicá, no sólo por medio de sus lanceros sino también como fuente de información sobre las ofensivas que se tramaban "tierra adentro". De este modo, a principios de mayo de 1855, el flamante jefe de la Frontera Sur informaba al ministro de guerra Bartolomé Mitre:

He dispuesto que el comandante Villar se acampe en Santa Catalina, con los ciento sesenta coraceros que hay aquí disponibles, cincuenta guardias nacionales y los indios de Maicó, manteniendo una partida de observación en el cerro de La Plata y otra en las puntas del Arroyo Azul. Para esta medida tengo en vista el anuncio de invasión de que da cuenta la nota del comandante de Bahía Blanca, el aviso que he recibido del cacique Maicó y de vecinos de Tapalqué. Por estos datos he reconcentrado toda la fuerza en el punto indicado, que, como usted ve, ascenderá á 250 hombres ${ }^{9}$.

Cabe destacar que la parcialidad de Maicá fue el único grupo indígena de Azul que no se había sumado a la gran sublevación catrielera y que, para entonces, entre sus integrantes revistaban oficialmente 33 lanceros (Ratto 2015, p. 94) que estaban encargados de vigilar ese sector particular de la frontera (Belloni, 2015, p. 145).

Ese mismo año de 1855 tuvieron lugar dos importantes batallas en las que fue derrotado el ejército de Buenos Aires por las fuerzas indígenas confederadas: Sierra Chica (31 de mayo) y San Jacinto o Tapalqué (29 de octubre). En ambas combatieron lanzas al mando de Maicá a favor del gobierno. En efecto, las tropas expedicionarias al mando de Bartolomé Mitre que lucharon en Sierra Chica contaban con un escuadrón de 60 "indios amigos", entre los que se encontraba un capitanejo hijo del propio cacique Maicá, que fue uno de los 16 muertos en dicha refriega ${ }^{10}$. De igual modo, las fuerzas del general Hornos que pelearon en San Jacinto estaban integradas por "el regimiento de coraceros, las milicias del Azul, y los indios de Maicá", bajo 
las órdenes del coronel Manuel Ocampo ${ }^{11}$. Sendas derrotas determinaron que el gobierno de Buenos Aires debiera volver a poner en marcha estrategias para pacificar la frontera que retomaron muchos elementos del "negocio pacífico" distintivo del período rosista (Ratto, 2015). Estas gestiones culminaron con la firma de tratados de paz con los caciques Catriel y Cachul en 1856, a la vez que se acordó la instalación de buena parte de las familias de la parcialidad liderada por Maicá en las inmediaciones del pueblo de Azul (cuyos pormenores se analizan en el apartado siguiente). Según se destacó, al año siguiente este último grupo formó una unidad de lanceros indígenas, que peleó en los combates de Sol de Mayo (31 de octubre) y Cristiano Muerto $\left(1^{\circ}\right.$ de noviembre) al mando de los coroneles Wanceslao Paunero y Emilio Conesa contra los caciques aliados a Calfucurá, que habían llevado a cabo un importante malón en los campos de la frontera Costa Sud (Del Valle, 1926, p. 124; Ronco, 1946, p. 19; Hux, 1993, p. 130).

Testimonios contemporáneos de primera mano, como la obra Usos y Costumbres de los Indios Pampas escrita por el coronel Federico Barbará, quien trató cotidianamente con los "indios amigos" de Azul, no dejan dudas sobre la situación de los lanceros de Maicá como cuerpo regular del ejército para este momento. Así, aclaraba Barbará, en sus "Palabras Preliminares", que la "tribu de Maiká, que es la que está en el ejército" le había corroborado parte de la información que había recabado "sobre las Costumbres de los Pampas; pero los indios de ella, en razón de hallarse bajo la dependencia del general en gefe, no pueden practicarlas del todo, como lo hacen los que no se encuentran en este caso...” (Barbará, 1856, pp. V-VI; énfasis nuestro). En especial, el militar hace referencia a sus conversaciones con Mariano Maiká, hijo del cacique, que "habla el español regularmente y posee muy buena inteligencia” (Barbará, 1856, p. 71). Para ese momento, la fuente detalla en otro apartado: "los que sirven a sueldo del Estado y que están agregados al regimiento de Coraceros No 2, son gobernados por un cacique llamado Maiká, los cuales viven con sus familias en el campamento del ejército." (Barbará, 1856, p. 46; énfasis nuestro). Este último dato es particularmente relevante si se tiene en cuenta que Barbará estuvo destinado en el Ejército de Operaciones del Sud entre noviembre de 1855 y mayo de 1856, es decir que, para ese momento, todo el grupo de Maicá -y no solamente los lanceros del mismo que revistaban- residía en instalaciones militares, desde donde se trasladó pocos meses después por la fundación de Villa Fidelidad en el pueblo de Azul.

\section{CRISIS Y PACIFICACIÓN DE LA FRONTERA: NUEVOS ACUERDOS Y TRATADOS}

\section{Catriel y Cachul, los "hijos de una misma tierra"}

En trabajos anteriores planteamos que las tierras fueron un elemento central, tanto en el origen del ciclo de violencia ocurrido entre 1853-1855 en la frontera sur como en la gestación de los acuerdos sobre cuyas bases el gobierno logró pacificarla nuevamente (Lanteri y Pedrotta, 2012; Pedrotta y Lanteri, 2016). Sin duda, fueron varios los factores que incidieron en los agudos conflictos interétnicos que acompañaron al cambio en la política indígena, iniciado un año después de la caída de Rosas, durante la gobernación de Pastor Obligado, entre los que se encuentran los planes de expansión de la frontera, la reorganización de sus comandancias, el cambio de las autoridades locales, el recorte del racionamiento para los "indios amigos" y la supresión del comercio (Lanteri, Ratto, de Jong y Pedrotta, 2011; Belloni, 2015; Ratto, 2015). Pero el hecho que detonó en última instancia la sublevación de los caciques Juan Catriel ${ }^{12}$ y Juan Manuel Cachul fue el intento de fundar, en sus tierras, el Nuevo Pueblo de Tapalqué. Hasta ese momento ambos caciques, pese a los mencionados cambios en la política de fronteras que se estaban poniendo en marcha, habían permanecido fieles a los acuerdos con Buenos Aires, ciertamente "alarmados, pero expectantes y en orden", según Cutrera $(2013, \text { p. } 4)^{13}$.

Vale repasar brevemente dichos sucesos. A comienzos de 1854 el flamante juez de paz de Tapalqué, Ezequiel Martínez, a solicitud de los vecinos, se encargó personalmente de realizar las gestiones para el traslado del Cantón de Tapalqué unas ocho leguas hacia el suroeste y obtuvo la autorización pertinente del 
gobierno, pocos meses después, para hacerlo sobre "la costa del arroyo Tapalqué, en los terrenos que fueron denunciados por los señores Terrero y Piñeiro" ${ }^{14}$. Tal como señalan Arena, Cortés y Valverde (1967, pp. 197-198), no fueron "los propietarios legales de esas tierras quienes se oponen a su ocupación, sino las tribus de Catriel que se consideraban auténticas propietarias por derechos de ocupación y concesiones obtenidas durante el gobierno de Rosas". En efecto, los “indios amigos” catrieleros habitaban y hacían uso de esas tierras al menos desde dos décadas atrás, en el marco del "negocio pacífico" que había sido puesto en marcha en los comienzos del período rosista ( Ratto, 2003; Lanteri y Pedrotta 2007, 2012; Lanteri, 2011) ${ }^{15}$. Sin embargo, el gobierno tomó la determinación de avanzar la frontera forzando el despojo de las tierras indígenas, por considerar que el traslado del cantón hacia las nacientes del arroyo Tapalqué "es conveniente y es el mejor modo de asegurar aquella parte de la Frontera, tanto porque domina los indios que quedan dentro de la línea, cuanto porque aleja a los que se hallan fuera de ella cortando sus comunicaciones" ${ }^{16}$. De esta resolución oficial se desprenden dos elementos importantes. En primer lugar, pese a ser considerados como "terrenos de propiedad pública", se reconocía tangencialmente que las tierras hacia las cuales se pretendía fundar el nuevo pueblo de Tapalqué estaban ocupadas de hecho por las tribus "amigas" y formaban parte de su territorio. En segundo término, se destacaba la centralidad del nodo Azul-Tapalqué dentro de las redes de interacción y de circulación (de información, bienes y personas) intraétnicas, cuya interrupción era, justamente, uno de los objetivos del pretendido avance criollo. 


\section{Figura 1}

Ubicación aproximada de las tierras de las tribus catrieleras, indicando la localización del pueblo de Azul, el Cantón Tapalqué y el lugar donde se intentó fundar el Pueblo Nuevo de Tapalqué en 1854

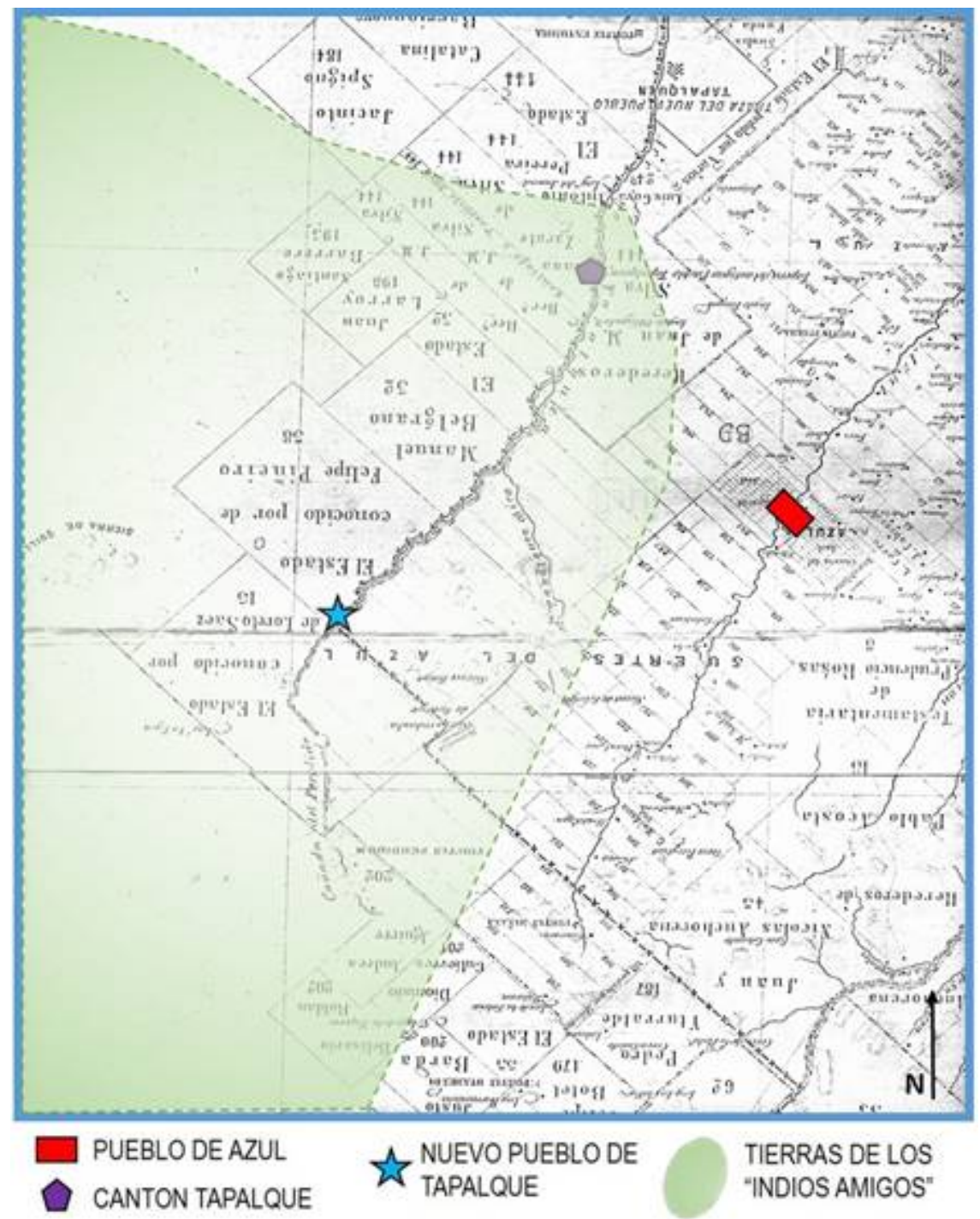

Fuente: elaboración propia con base en el Registro Gráfico Provincial de 1864

Los preparativos para la nueva fundación continuaron, en el marco de un proyecto mayor del recientemente nombrado ministro de guerra y marina, Bartolomé Mitre, para avanzar toda la línea de la frontera sur ${ }^{17}$. Tal como ha sido señalado (Ratto, 2015, pp. 87-88), este giro en la política indígena del gobierno liberal tensó las relaciones con los principales caciques "amigos" y llevó a un cambio en las alianzas inter e intraétnicas, activando las "relaciones indígenas que cruzaban el espacio fronterizo y llegaban hasta el corazón del territorio indígena.....En este caso, la conflictividad se ubicaba dentro de -y era generada por- la política provincial bonaerense, lo que llevó a que esos contactos pacíficos se redireccionaran hacia la búsqueda de alianzas políticas en contra del gobierno porteño". Ante dicha coyuntura, los caciques Catriel y Cachul optaron por resistir abierta y armadamente el despojo de sus tierras dando fin a los acuerdos pacíficos que hasta ese momento mantenían con el gobierno. Así, en mayo de 1855, los catrieleros asaltaron unas carretas con pertrechos para el campamento que se había instalado en las nacientes del arroyo Tapalqué, apresaron al juez de paz Ezequiel Martínez junto con dos vecinos, y mataron a un policía y al capataz del convoy, entre otras personas ${ }^{18}$. Poco después, destruyeron el incipiente poblado cuya fundación se había llevado a cabo unos 
meses antes ${ }^{19}$. Paralelamente, los otrora "indios amigos" se unieron a la confederación indígena liderada por Calfucurá y encabezaron malones, que fueron realizados sobre las estancias y poblados de toda la frontera sur con particular violencia, a la vez que combatieron contra las tropas del ejército. En palabras del propio B. Mitre, los "indios de Calfucurá y de Cachul y de Catriel y de los demás príncipes de la pampa coligados" desataron así "una de las más formidables tempestades que hayan descargado sobre la frontera" ${ }^{20}$. Mientras tanto, el grueso de la tribu catrielera se trasladó hacia la zona del río Sauce Grande, en el suroeste bonaerense, para asegurar así la protección para sus familias.

El ciclo de conflictividad interétnica, ante el cual se hizo evidente la incapacidad del gobierno de dominar militarmente a las tribus sublevadas ${ }^{21}$, llevó al despoblamiento criollo de gran parte de la campaña centrosur entre 1853 y 1855 , con el consiguiente retroceso de la frontera estatal que había sido forjada especialmente durante el período rosista. Esta crítica coyuntura obligó a las autoridades del Estado de Buenos Aires a retomar el camino de la pacificación por medio de tratados con los principales caciques del sur: Calfucurá, Yanquetruz, Catriel y Cachul, con quienes se logró consensuar diferentes acuerdos, más o menos formales, en cuya gestación fue clave la intervención de los comandantes militares de los fuertes fronterizos (Levaggi, 2000). Como han destacado investigaciones previas (Roulet, 2004; Pérez Zabala, 2005, por ejemplo), es fundamental para la comprensión de los tratados interétnicos el análisis no sólo del producto finalmente escrito y conservado sino también el de los antecedentes, entramados diplomáticos y relaciones de poder involucrados en su gestación, como intentaremos desarrollar a continuación.

En el caso de los "indios amigos" catrieleros, las negociaciones fueron especialmente complejas y se llevaron a cabo en varios frentes simultáneos. En ellas debió intervenir personalmente el propio gobernador Pastor Obligado, quien se trasladó a Azul a fines de febrero de 1856 "para ir a auxiliar al ejército como pueda" dada la grave situación en que se hallaba ese sector de la frontera y el pedido de renuncia que había presentado el abatido general Hornos ${ }^{22}$. La cuestión territorial fue de importancia central en los nuevos acuerdos y, de hecho, la intervención directa de Obligado y su promesa escrita de respetar las tierras de los caciques Catriel y Cachul fue la condición que posibilitó el inicio de dichas gestiones. De este modo, en una carta a su "Apreciado Catriel", el gobernador le aseguraba:

si nosotros hemos de hacer nuevos pueblos en los campos, y nuevas chacras y quintas y estancias, no ha de ser quitándoles por la fuerza los campos que vos y tu gente tienen, sino haciendo buenos arreglos para poblar esos campos del otro lado de las sierras, para que todos quedemos contentos y podamos comerciar bien (...)Todas estas razones te las explico bien claras, como hermano de buen corazón, que me intereso mucho por tu bien y el de todos los indios, y para que no corra más sangre, ni tengamos más desgracias, no vas á engañarte, y á creer vos que todo esto que te digo es porque tengamos miedo, y que por eso queremos hacer la paz (...) como buenos hermanos, hijos de esta tierra, no queremos que corra sangre de los hombres que han nacido todos en esta misma tierra 23

En las pomposas declaraciones de Obligado aparece una dimensión substancial, no material, de la territorialidad, que se vincula con la identidad y la pertenencia de unos y otros a la tierra, como elemento que "hermana" a quienes nacieron en ella, como una suerte de fuerza cohesionadora simbólica a la que se acude en lo discursivo como fundamento para lograr la conciliación, de la cual quedaba a la vez oportunamente excluido el cacique "enemigo" Juan Calfucurá, por ser "chileno". ${ }^{24}$

Luego de la renuncia de Hornos, en junio de 1856 se designó como nuevo jefe de la Frontera Sur al general Manuel Escalada, con la pacificación como misión principal. Las negociaciones con Catriel y Cachul prosiguieron, y se sumó a las comunicaciones directas remitidas por Obligado y Escalada el envío de una comitiva diplomática que estuvo encabezada por el coronel Ignacio Rivas, dos vecinos y una escolta de soldados veteranos a las tolderías del río Sauce Grande, donde se llevaron a cabo entrevistas y parlamentos (Del Valle, 1926, pp. 221-222). Desde el Fuerte Argentino, al mando del teniente coronel Juan Susviela, también se emprendieron tratativas de paz que fueron encomendadas al sargento mayor Francisco Iturra, 
quien inició un intercambio epistolar con Juan Catriel. El cacique manifestó entonces que tanto él como Juan Manuel Cachul tenían:

la mejor disposición de tratar la paz tan deseada por nosotros como por los cristianos, porque sabemos que la paz es la única garantía con que asegurarnos nuestras vidas, familias e intereses, y que solamente aguardamos que el Superior Gobierno de la Provincia nos presente las bases, sobre que debemos tratar y afianzar una eterna unión ofensiva y defensiva sobre todos enemigos que traten [de] hollar nuestros derechos ${ }^{25}$.

Debe resaltarse que en esta carta se argumenta ostensiblemente -desde la perspectiva indígena- que las relaciones pacíficas y las alianzas bélicas ante terceros eran partes indisolubles en los acuerdos interétnicos que, en esa coyuntura, se esperaba concretar. Ambas cuestiones, puestas deliberadamente en la agenda de negociaciones por los caciques, fueron retomadas en toda la correspondencia posterior, y se plasmaron en los artículos $1,11,12,13,15,17$ y 18 del tratado que finalmente se firmó, como se verá más adelante.

Para avanzar en las gestiones de paz a nivel local, Susviela e Iturra enviaron una comisión en representación del pueblo de Bahía Blanca a los toldos del ahora "Cacique General del Sauce Grande Don Juan Catriel”, ya que él se había excusado de concurrir allí para "una conferencia privada" ${ }^{26}$ porque aguardaba noticias del general Escalada desde Azul -a donde debía llegar en agosto- "para entenderse en asuntos de la paz", según indicaciones del gobernador Obligado (Levaggi, 2000, p. 294). La comisión que partió desde el Fuerte Argentino llevaba instrucciones precisas que no incluían explícitamente la cuestión territorial. Según tales instrucciones, se debía trasmitir al cacique y su grupo el "deseo que nos asiste á nosotros, que en adelante compongamos una sola familia, como hijos de una misma tierra", con la propuesta de un acuerdo que se basaba en el compromiso de no atacarse, de dar aviso en caso de invasiones, de apoyo militar recíproco, de prestar auxilio militar a Catriel y dar refugio y protección a sus familias en el pueblo en caso de "rompimiento" entre caciques. Por su parte, Catriel se comprometía a devolver a los desertores cobrando $\$ 300$ por cada uno; otras cuestiones que eventualmente se trataran debían ser consultadas posteriormente con el gobierno ${ }^{27}$. Con todo, la carta que envió el comandante Susviela a Catriel con dicha comitiva, a tono con la línea argumental de las misivas previas del gobernador Obligado y del propio cacique, refiere en forma directa a "la tierra", cuya conservación y defensa -afirmaba- eran los pilares de los acuerdos interétnicos que debían hacerse, solidarizándose ambas partes ante eventuales ataques de otros grupos indígenas. En efecto, la comitiva debía transmitir al cacique y a su gente los

buenos deseos por estrechar del todo nuestra amistad, haciendonos utiles los unos á los otros, pues estos manifestaran á V. el medio de realizarlo, que con el conservaremos nuestra querida tierra y nos haremos respetados de los enemigos, tanto los que Vs. tengan, como los tengamos nosotros pues estos su deseos no son otros que hacerse dueños de la tierra que á $V$. y a nosotros nos pertenece.... 28

Juan Catriel -en su respuesta del 8 septiembre- expresó su acuerdo pleno con dichas bases para la pacificación:

Emos conbenidos respetarnos ambos, en nuestras relaciones de Amistad...Nos hemos obligado tambien auciliarnos y defendernos con nuestras fuerzas de todo enemigo fuera de la Probincia Argentina que inbada nuestra tierra; y cuando fuece Enemigo que pertenesca ha los que estamos aliados ambos nos emos obligados, de entrar ha mediar como tercero En discordia" ${ }^{29}$.

En esta última misiva queda más claramente formulada la amenaza potencial que percibían los catrieleros con respecto a enemigos internos o externos que podían "invadir" sus tierras, para cuya defensa consideraban coyunturalmente ventajoso sellar un pacto de amistad y solidaridad militar con el Estado de Buenos Aires ${ }^{30}$.

El 26 de octubre de 1856, en Azul, se acordó la "Convención de Paz" definitiva entre el Estado de Buenos Aires, representado por el general Manuel Escalada y Juan Catriel "Cacique Mayor de las tribus del Sud" y "su segundo” Juan Manuel Cachul, “por sí y á nombre de sus respectivas Tribus, con el objeto de poner término 
á la guerra y regularizar para lo sucesivo las condiciones de existencia y comercio” ${ }^{31}$. El artículo segundo de los veintiuno que integran el tratado toca de lleno la cuestión territorial, y estipula que:

las Tribus de estos Casiques, con la venia y consentimiento del Gobierno, se establecerán al Oeste del Arroyo Tapalqué, en una área de veinte leguas de frente y veinte de fondo, cuyos límites se fijarán por el ingeniero del Ejército, si es posible que sean naturales, y con asistencia de ellos; los cuales, el Gral. en Gefe, se los dará en propiedad á las mencionadas Tribus, para que vivan allí pasíficamente ejerciendo su industria y cultivando la tierra para su sustento ${ }^{32}$.

Mediante el artículo tercero se dejaba constancia de la entrega

de los medios necesarios (...) para que con ellos edifiquen sus casas habitaciones, el Cacique Mayor D. Juan Catriel y su segundo D. Juan Manuel Cachul y algunos otros caciques menores, y además por una sola vez les dará arados y semilla para que hagan cultivar la tierra en su beneficio ${ }^{33}$.

El artículo quinto aclaraba más adelante que cuando los indígenas se estableciesen en "aquel punto" podrían "hacer boleadas en el campo que ocupen para su comercio de peletería reglamentando la operación á fin de no causar perjuicios á los colindantes" ${ }^{34}$. De este modo, en las primeras cláusulas del tratado quedaban asentados los pilares de la pacificación para las tribus catrieleras: un territorio propio de veinte leguas cuadradas (unas 54.000 hectáreas), viviendas, herramientas e insumos para el cultivo de la tierra y campos para cazar y bolear ñandúes. El convenio contemplaba asimismo otras cuestiones sin duda importantes, tales como el restablecimiento del comercio, el racionamiento trimestral a las tribus "amigas", el rescate de cautivos y los nombramientos militares con sus remuneraciones respectivas para los jefes y los lanceros indígenas.

Como se ha planteado en trabajos previos, por medio del tratado de 1856 el Estado de Buenos Aires reconoció derechos en "legítima propiedad" a los "indios amigos" catrieleros sobre veinte leguas cuadradas situadas al oeste del arroyo Tapalqué, cuya delimitación y mensura, pese a haber sido prevista, no se concretó posteriormente (Lanteri, Ratto, de Jong y Pedrotta, 2011; Lanteri y Pedrotta, 2012). Las nuevas fuentes consultadas indican que no sólo el deslinde de dichas tierras fue motivo de disputas irresueltas entre las autoridades del gobierno y los caciques, sino también su ubicación y extensión. Bartolomé Mitre pretendía que los campos para "correrías y boleadas" estuvieran alejados entre veinte y treinta leguas del territorio poblado por los criollos y que los indígenas debían dejar libre "todo lo que comprende desde los caminos de Tandil a Bahía Blanca y Patagones hasta la costa del mar" 35 . En contraste, Catriel y Cachul reclamaban en exclusividad una superficie muchísimo mayor, que excedía con creces las 20 leguas, y que abarcaba las tierras situadas inmediatamente al oeste de las Sierras Bayas, tal como dejaron expresamente asentado en una carta enviada a Escalada dos meses luego de la firma del tratado:

nuestros campos quedan por Usted [el general Escalada] reconocidos a nombre del Supremo por legitima propiedad de la Cierra de Cura Malal hasta la de Bayucura [Sierras Bayas], sirviendo esta ultima de limite para ambos sin poder traspasar esta línea ni los cristianos a esta parte ni los indios a la otra por ningún pretesto, y solamente podrán unos y otros pasar a comercio ${ }^{36}$. 


\section{Figura 2}

Extensión aproximada de las tierras reconocidas por el tratado de 1856 a las tribus “amigas" de Catriel y Cachul según ellos mismos

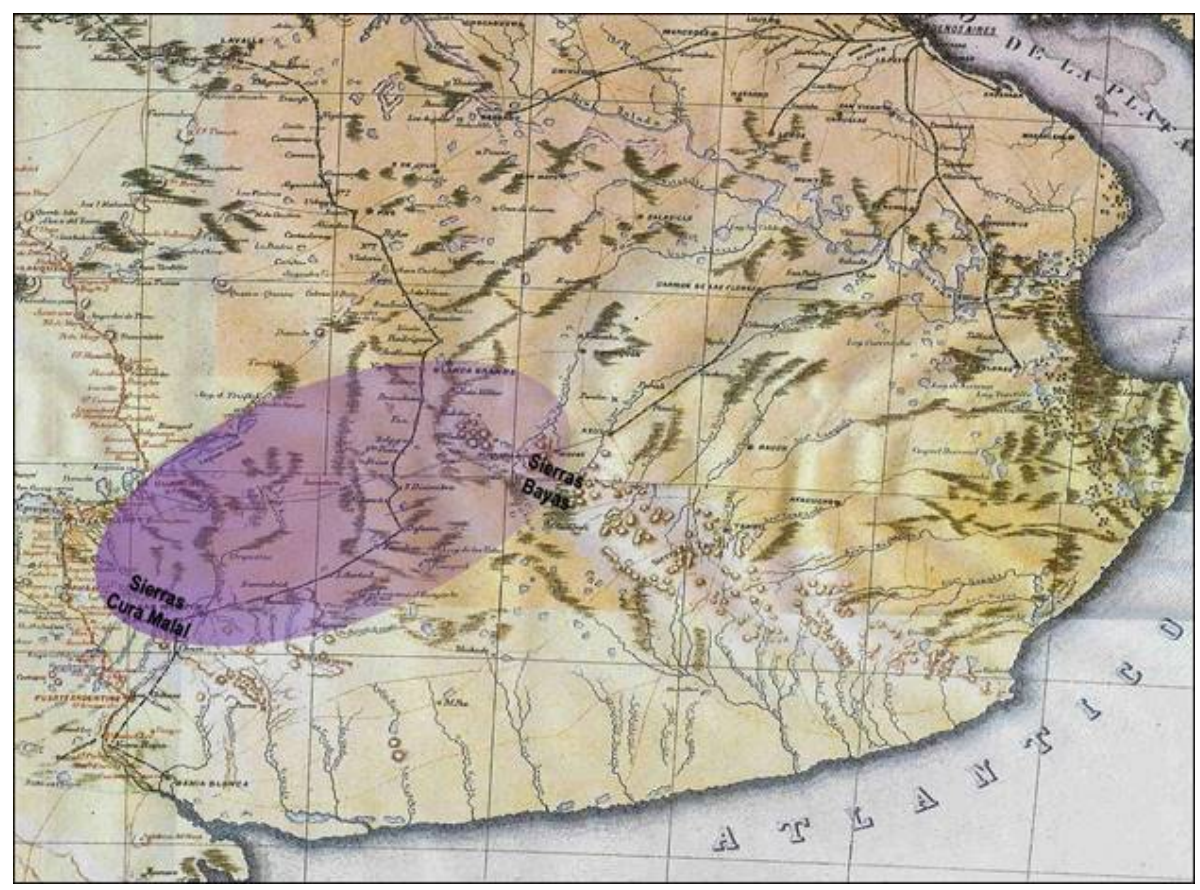

Fuente: elaboración propia con base en la carta de dichos caciques a M. Escalada del 23-12-1856, sobre el "Plano general de la nueva línea de fronteras sobre la Pampa" de J. Wysosky, 1877

Vale destacar aquí, que además de que superficie del territorio reclamado era enorme, también lo era su importancia geopolítica, dado que estaba ubicado en el epicentro de los caminos y rastrilladas que comunicaban el asentamiento nodal de "indios amigos" de Azul-Tapalqué con las tribus situadas al sur y oeste de la frontera bonaerense, con el territorio ranquelino, con grupos de la zona cordillerana y el norte de la Patagonia, lo que favorecía el control del intercambio de personas, bienes e información en un extenso espacio $^{37}$.

El general Escalada, por su parte, reconocía que las cuestiones de límites habían formado parte de la agenda de negociaciones propuesta por los caciques (quienes le "indicaron" que las tierras debían situarse entre las Sierras Bayas y la Sierra de Cura Malal), pero también afirmaba no haber aceptado tal requerimiento, sino sólo haberles reconocido las tierras donde ya vivían las tribus "amigas"

Sientan los caciques Catriel y Cachul un principio falso cuando dan por reconocido por mi a nombre del Gobierno, los deslindes de las Sierras Cura Malal y Bayu-Curá que ellos indicaron entonces y que yo evadiendo la contestación categórica sólo dije reconocerlos como estaban antes en sus campos de Tapalqué; y esto mismo pienso decirles en contestación, agregando que ese punto quedará por ahora en suspenso hasta que ellos lo arreglen directamente con el Gobierno del Estado ${ }^{38}$.

De este modo, es claro que la extensión, ubicación y el deslinde de las tierras fueron tema de las gestiones de paz que culminaron con el tratado de 1856, pese a que no se resolvieron las discrepancias al respecto. En los hechos, luego del convenio de paz, las tribus se reinstalaron efectivamente en los campos ubicados al oeste del arroyo Tapalqué, en las mismas tierras donde habían vivido antes de la sublevación de 1853-55, y durante el rosismo en el marco del "negocio pacífico". Aunque no figura explícitamente en los registros gráficos provinciales de tierras públicas coetáneos, la localización de dichos terrenos sí fue registrada en otras fuentes cartográficas, así como en un variado corpus -contemporáneo y también posterior- de documentos inéditos y obras publicadas ${ }^{39}$. En este nuevo escenario, al poco tiempo, las tribus pampas de Lucio López y su hijo Chipitruz, Calfuquir, Cholaylaf y Comihuala se instalaron también en la zona, en tanto Catriel aceptó que el nuevo fuerte y pueblo de Tapalqué - actual ciudad de Olavarría- fuera construido en sus tierras. 


\section{La FUndación de Villa Fidelidad}

Paralelamente, el general Escalada gestionó la entrega a los “indios amigos" de lotes que estaban ubicados en las inmediaciones del pueblo de Azul y que dieron origen al actual barrio de Villa Fidelidad, un caso que reviste particular interés por varios motivos. En primer lugar, porque se trató de una modalidad totalmente inédita de otorgamiento de tierras a indígenas que no fue colectiva sino a título individual-familiar. Escalada compró a la Corporación Municipal ${ }^{40}$ un predio situado al oeste del arroyo Azul, dentro de la traza del pueblo y su ejido, un segundo elemento muy llamativo, ya que las demás tierras en la frontera bonaerense, que fueron objeto de reclamos y/o entregas a los "caciques y sus tribus", estaban mayormente situadas en áreas rurales o en la frontera. Dicho predio fue dividido en cien solares de 50 varas de frente por 50 de fondo, los cuales se organizaron siguiendo un modelo en damero, alrededor de una plaza central cuadrada de 100 varas de lado 41. Aquí resalta otra singularidad de Villa Fidelidad, ya que la traza en damero no reconoce antecedentes en los patrones de ordenamiento espacial indígena previos ni contemporáneos (Pedrotta y Lanteri, 2016). De esos cien solares, 47 fueron inmediatamente adjudicados en propiedad individual mediante un boleto que fue rubricado por el propio Escalada. Según la información disponible hasta el momento, se trata del único caso de otorgamiento de predios en propiedad individual a "indios amigos", que recibieron solares en la traza urbana, en un sector especialmente destinado para ese fin, donde no había hasta entonces población indígena establecida ${ }^{42}$.

Los adjudicatarios iniciales de los solares de Villa Fidelidad fueron: Juan Medina (1), Roque Maicá (2), Juan Jose Sañico (3), Calisto Vidal (4), Tomas (5), Mariano Catrimilla (6), Manuel Torres (7), Andres (8), Juan Peña (9), Luciano Maicá (10), Manuel Antonio (11), Jose María Medina (12), Nazario Martínez (13), Jose Chico (14), Manuel Upuara (15), Antonio Nouqué (16), Juancho Pallaquice (17), Ramón Millagües (18), Federico (19), Jose María Posada (20), José María López (21), Santos Colvan (22), Maciel Rojas (23), Manuel Cabral (24), Juan Rufino (25), Jose Rojas (26), Rufino Alvornos (27), Rondan Chico (28), Martin (29), Jose Carrizo (30), Mariano Sinco (31), Pedro Torres (32), Jose Marmol (33), Luciano Ponce (34), Nicolas Gonzalez (35), Bartolo Antifilu (36), Antonio Samuel (37), Pancho Francisco (38), Robustiano Villapan (39), Casiano (40), Carlos (41), María (42), Manuela Maicá (43), Rosa Maicá (44), Juana (45), Carmel (46) y Manuela Rosa (47) ${ }^{43}$. El cotejo de la nómina con la lista de revista de la Compañía de Indios del Azul, de octubre de 1857, al mando del cacique Rafael Maicá, permite confirmar que este grupo fue el principal beneficiario del reparto inicial de los solares de Villa Fidelidad ${ }^{44}$. En efecto, diez de los doce oficiales - un "caciquillo", seis capitanejos y tres sargentos- que integraban dicha compañía recibieron solares. En muchos casos se indica en las fuentes el grado militar que ostentaban los distintos adjudicatarios (capitán mayor, capitán, indio capitán o soldado), que respetaba el ordenamiento militar indígena. Más interesante aún es que las únicas seis mujeres que recibieron solares figuran con la condición de viudas, lo que nos lleva a plantear que muy probablemente sus respectivas parejas deben haber perecido en acciones bélicas. Además, a Mariano Maicá le fue entregado de forma distintiva un terreno que estaba significativamente ubicado de forma contigua a otro del cacique Catriel (Sarramone, 1993, p.180). 
Figura 3

Ubicación relativa de las 20 leguas cuadradas y de Villa Fidelidad

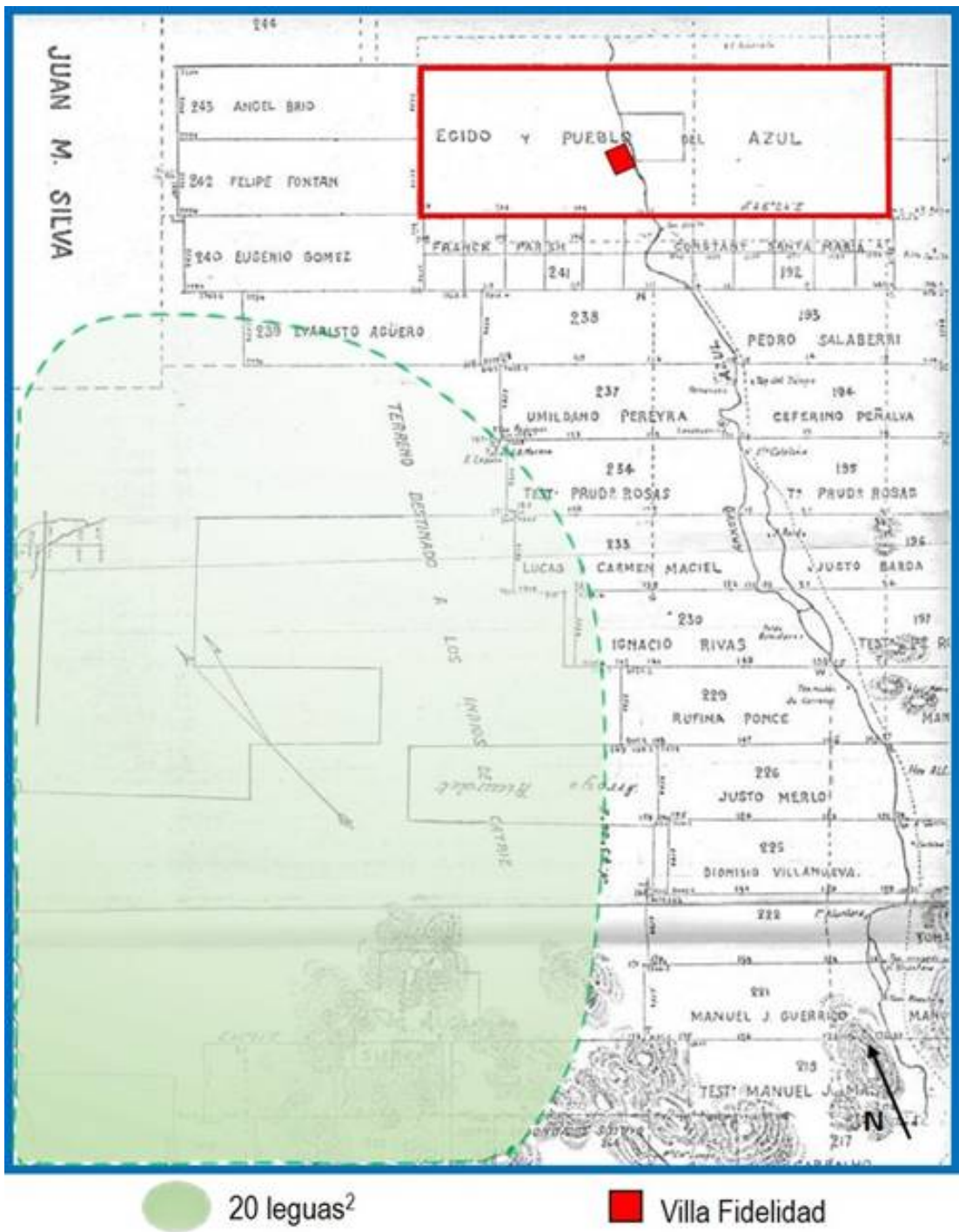

Fuente: elaboración propia con base en el "Plano de las Suertes de Estancia del Azul” de J. Dillón, 1872

Para comprender la singular génesis de Villa Fidelidad, así como la obtención privilegiada de tierras, fundamentalmente por parte de la parcialidad de Maicá - que contrasta tanto con las veinte leguas cuadradas que en simultáneo le fueron reconocidas a los caciques Catriel y Cachul como con todas las demás entregas de tierras en propiedad comunal a distintos caciques y sus tribus efectuadas en la frontera sur y oeste durante las dos décadas siguientes-, es clave tener en cuenta, como conjeturamos en trabajos previos, la posición que mantuvo Maicá frente al ciclo de violencia interétnica fronteriza de esos años (de Jong, Lanteri, Pedrotta y Ratto, 2009; Lanteri, Ratto, de Jongy Pedrotta, 2011). En el apartado anterior se reseñó la destacada actividad bélica que tuvo el cacique y su tribu en esa coyuntura: enfrentó regularmente a otros grupos indígenas no aliados, y mantuvo su lealtad inamovible al gobierno porteño, a diferencia de otras parcialidades "amigas". Según el análisis de las listas de revista de los distintos cuerpos del ejército bonaerense efectuado por Ratto (2012, p. 367; 2015), la división de lanceros indígenas comandados por Maicá era la principal milicia de "indios amigos" que existía en toda la frontera sur (Azul, Tapalqué y Bahía Blanca) en 1855, junto a los de Collinao, Cayupulqui y Teuque, y la única si se considera sólo la primera localidad. No casualmente, a partir de entonces la compañía del cacique Maicá comenzó a revistar como un cuerpo auxiliar estable. Estos datos, junto a la diversa y consistente evidencia presentada en este trabajo, permiten afirmar que la entrega de tierras 
funcionó como contrapartida del servicio armado de los Maicá, cuya trayectoria se plasmó en la creación de Villa Fidelidad, un emplazamiento urbano sui generis que, según la información disponible, no reconoce antecedentes ni experiencias similares coetáneas en otros sectores de la provincia de Buenos Aires.

\section{Conclusiones}

Nos propusimos en este trabajo profundizar el análisis de la territorialidad de los "indios amigos" en la frontera sur de la provincia de Buenos Aires haciendo foco en dos modos diferentes y simultáneos de acceso a la tierra, que se plasmaron en 1856: por un lado, el reconocimiento de veinte leguas cuadradas comunales en cabeza de los caciques Catriel y Cachul, y por otro, la formación del enclave urbano de Villa Fidelidad, donde se entregaron solares a determinados individuos y/o familias mayormente pertenecientes a la parcialidad liderada por el cacique Maicá. Para su comprensión atendimos a coordenadas que consideramos centrales en el contexto de la expansión criolla y oficial de la frontera bonaerense, su interacción con la sociedad indígena y las disputas y reconfiguraciones territoriales en el marco del nuevo "negocio pacífico" que debió reformularse luego del período abierto con Caseros y el sitio de Lagos.

Sin duda, una de las claves para entender ambos casos es analizarlos en el marco de la convulsa década de 1850 y de la consecuente redefinición de la política del "negocio pacífico", de las redes de relaciones interétnicas, y de la importancia que representó para el Estado de Buenos Aires el auxilio militar indígena frente a su regular confrontación bélica con la Confederación en tiempos de la conformación institucional de la república. En este sentido, si bien en estudios anteriores (Lanteri y Pedrotta, 2012) consideramos que el reconocimiento de derechos sobre las veinte leguas cuadradas a las tribus catrieleras por medio del tratado de octubre de 1856 y la entrega de solares en Villa Fidelidad habían sido parte de una política más amplia -aunque no homogénea-, que continuó con la entrega de tierras en propiedad a otros grupos de "indios amigos" en la provincia a partir de la década de 1860, el avance de la pesquisa y la consulta de otras fuentes de evidencia nos conducen ahora a redefinir nuestra postura, en cuanto entendemos que fueron dos casos singulares, diferentes de los posteriores e inteligibles sólo en la coyuntura de mediados de 1850s.

Por otra parte, hemos podido confirmar la hipótesis que habíamos planteado previamente (de Jong, Lanteri, Pedrotta y Ratto, 2009; Lanteri, Ratto, de Jong y Pedrotta, 2011) sobre la contraprestación de bienes (tierra) por servicios públicos (apoyo militar) y el surgimiento de Villa Fidelidad como recompensa a la lealtad militar. Hemos subrayado que Maicá y su grupo ya estaban prestando servicio armado desde la década de 1830, pero a diferencia de otros, como los comandados por los caciques Catriel y Cachul, se mantuvieron alineados con el gobierno provincial de forma constante; lucharon incluso contra ellos y contra otros indígenas que hostilizaban la frontera, en particular en la coyuntura de 1853-55, que fue especialmente crítica para el gobierno. Quizás esto permita entender también la concentración de esta tribu "amiga" y fiel en el asentamiento urbano, frente a la mayor independencia que tenían las tolderías de Catriel y Cachul que, aunque cercanas, se encontraban a unas leguas del pueblo en el espacio fronterizo más abierto. Si bien la entrega de tierras como retribución por el servicio armado no constituía una novedad en el contexto de las políticas oficiales que se habían llevado a cabo anteriormente en la frontera y en la campaña de Buenos Aires con la población criolla, entendemos que esta particular donación de predios urbanos replicó de cierta forma lo sucedido en la zona de Azul con otros sectores sociales durante el período rosista (ver Lanteri, 2011 y 2017).

Es dable remarcar la importancia de esta contraprestación de bienes por servicios y la compensación por el auxilio armado, ya que se traducen en fidelidad y sostén político en una década convulsa y plagada de enfrentamientos entre dos Estados en formación hasta la unificación del Estado Nacional a partir de la presidencia de B. Mitre en 1862, que tuvo su correlato en la frontera. El servicio armado de Maicá y su gente fue anterior a 1856, e incluso lo traspasó brindando un servicio regular y no esporádico o puntual. De hecho, sabemos que la parcialidad estaba regimentada y constituía parte del ejército provincial como guardia 
nacional y otros cuerpos de línea y milicia. Además, Maicá y su tribu recibían un trato diferencial con respecto a otros grupos: vivían dentro del campamento del ejército y fueron relocalizados dentro del territorio oficial a partir de la fundación de Villa Fidelidad en el pueblo de Azul, cobraban un sueldo mensual y recibían un racionamiento regular por separado -a diferencia de otros "indios amigos"- por lo menos hasta fines del decenio de $1850^{45}$.

Como ha sido planteado (Ratto, 2006; Lanteri y Pedrotta, 2012; Belloni, 2015), el tratado de 1856 y sus implicaciones fueron producto más de la incapacidad militar oficial frente a las fuerzas indígenas que de una política estatal de expansión militarizada como la que hubo posteriormente. En este sentido, debemos ser cuidadosos para no caer en anacronismos como el que advirtió Langer (2003) en relación con la mirada retrospectiva que se tiene desde los siglos XX y XXI del inevitable triunfo de los criollos y los Estados nacionales sobre los pueblos nativos, algo que no era nada claro en el momento de los acontecimientos. De hecho, el autor destaca, en una escala continental, al período de 1824-1860 como de "superioridad militar indígena”, seguido por uno de transición (1860-80), durante el cual la tendencia comenzó a invertirse. Entendemos que es dentro de estos lineamientos que debería considerarse la gestación de las paces, que si bien se firmaron en el mes de octubre con la anuencia de Calfucurá -dentro de la relativa independencia de cada cacique en un sistema de manejo de información y negociación colectiva-conllevaron varios meses de tratamiento, e involucraron a diversos agentes en un marco de relaciones intraétnicas e interétnicas complejas. Vale destacar aquí el rol de Rivas y del mismo gobernador provincial Pastor Obligado, quien se apersonó en la frontera. A diferencia de los pactos interétnicos realizados durante el gobierno de Rosas y de la oralidad característica de las sociedades nativas, el de 1856 fue estipulado por escrito. Aquí cobra capacidad operativa asimismo lo planteado por Bechis (1989) sobre la organización política "segmental" indígena, que operaba por fisión y fusión de grupos, por la que los caciques tenían cierta autonomía y, en la medida que lograran consenso al interior de su parcialidad, podían establecer acuerdos en forma independiente con las autoridades locales. Esto explicaría también por qué Maicá se alistó y vivió en el campamento militar del fuerte Azul, mientras otros caciques como Catriel y Cachul mantuvieron situaciones y condiciones de acuerdos distintos.

En contraste con la marginalidad otorgada por otros estudios a la relevancia de las tierras indígenas en el tratado de 1856, ratificamos lo que habíamos planteado (Lanteri y Pedrotta, 2012) sobre su lugar nodal, tanto en la conflictividad posrosista, a partir de 1853, como en gestación de las paces y en el establecimiento de Villa Fidelidad. La noción flexible de territorialidad que trazamos entonces y su utilidad como herramienta de negociación con el Estado queda nuevamente confirmada, pues, como vimos, un mismo grupo de "indios amigos", como el de Maicá, se acomodó a un uso del espacio distinto al de otros, e incluso a sus propias tradiciones previas. De forma paralela, la centralidad de la tierra y el reclamo de su "legítima propiedad" por parte de los propios indígenas en las negociaciones con el Estado es dable de subrayar otra vez, porque a pesar de que finalmente no les otorgaron los títulos de propiedad a las tribus de Catriel y Cachul, el reconocimiento oficial de las 20 leguas cuadradas se dio de forma bastante temprana (en relación con otros grupos de "indios amigos" en distintos sectores de la frontera que recién reclamaron tierras en la década de 1860) e intentó refrendarse formalmente "al cacique y su tribu" en 1872, aunque esto no se hubo de concretar (Barbuto, 2014; de Jong, 2015, pp. 109-110). De hecho, según la información disponible, el acuerdo de 1856 constituyó el primer tratado escrito durante el período Independiente -que llegó hasta nuestros días- mediante el cual se reconoció oficialmente la legítima propiedad de tierras a una comunidad indígena en Buenos Aires. Su importancia resalta a tal punto, que en las negociaciones previas a la firma del tratado con Yanquetruz que se concretó en mayo de 1857, este cacique, quien conocía los términos en que la provincia había pactado con Catriel, expresaba "los más vehementes deseos de realizar una paz bajo idénticas condiciones" pues las reconocía "inmejorables" 46.

A través de las fuentes documentales analizadas hemos podido abordar algunas dimensiones de la territorialidad de los grupos nativos. Por un lado, ésta refiere a un hábitat o espacio físico que debe garantizar su reproducción social y que, en el caso de los “indios amigos” catrieleros, comprendía una extensión de tierras 
propias (unas 54.000 hectáreas), viviendas, herramientas e insumos para el cultivo, y campos para cazar y bolear ñandúes, tal como se acordó en el tratado de 1856. Por otro lado, hemos remarcado también una dimensión no material del territorio que se vincula con los orígenes de unos y otros, con un sentimiento de arraigo al cual criollos e indígenas aluden -en el plano discursivo- como fundamento para considerarse "hermanos", en tanto hijos de la misma tierra y también como fuerza cohesionadora que los lleva a aliarse mutuamente ante potenciales amenazas externas. En este sentido, ha sido posible acceder a la perspectiva y la agencia indígena, principalmente a través de la correspondencia escrita en nombre de los caciques Catriel y Cachul (y extensivamente de todos sus seguidores, en virtud del tipo de autoridad que tenían y del necesario consenso para acuerdos de esta naturaleza) donde exponen sus motivaciones, objetivos y condiciones de cara a las negociaciones de paz. Esto contrasta con el grupo de Maicá, acerca del cual no hemos podido indagar hasta el momento con el mismo grado de detalle.

El emplazamiento de las tolderías catrieleras en la frontera exhibe ciertos contrapuntos con el asentamiento urbano de Villa Fidelidad. La consabida importancia demográfica y la permanencia territorial de aquellas tribus en la zona desde hacía décadas generó el reconocimiento en "legítima propiedad" de tierras que ya usufructuaban previamente, a diferencia de las donaciones de solares en el entramado del pueblo de Azul, que constituyeron una instalación sui generis. En este sentido, Villa Fidelidad puede ser considerada como un "enclave étnico abierto" urbano dentro del territorio oficial, contiguo a las tolderías -y cabe preguntarse hasta qué punto complementario con ellas-, en estrecho contacto con la multietnicidad de otros grupos indígenas y no indígenas de la frontera. Finalmente, otra diferencia que muestra la singularidad del caso, en virtud de la heterogeneidad de situaciones sobre tierras de "indios amigos" en la provincia -además de su temprana fecha y de tratarse de una experiencia novedosa-, es que las donaciones no se hicieron mediante la modalidad comunal sino en propiedad individual-familiar ${ }^{47}$, y si bien se registraron solicitudes y donaciones de solares o predios a otros caciques y sus tribus en distintos lugares de la frontera y en las trazas urbanas de algunos pueblos como Bragado, 25 de Mayo, etc., incluso a modo de premio militar (Literas, 2015 y 2016; Literas y Barbuto, 2015; de Jong, 2015; Martinelli y Acosta, 2016), no se manifestaron de una forma tan concentrada geográfica y poblacionalmente. En contraste con las demás situaciones mencionadas, en la creación de Villa Fidelidad parece que el Estado tuvo un rol más activo, ya que la donación partió "de arriba hacia abajo" y no se debió, hasta lo que sabemos, a un requerimiento de los propios indígenas. Finalmente, el origen y desarrollo de esta singular "toldería suburbana" se hace inteligible en tanto premio a la lealtad militar sostenida dentro de la crítica coyuntura política, militar e institucional de la conformación republicana durante la década de 1850 -particularmente el lapso de violencia interétnica fronteriza de 1853-55-, lo que abre nuevos interrogantes y líneas para continuar con su análisis (Lanteri y Pedrotta, 2017).

\section{ReFERENCIAS}

Archivo del General Mitre (1912). Cartas confidenciales de varios sobre diversos asuntos, Años 1854-57, Tomo XV, Buenos Aires, Biblioteca de la Nación.

Arena, J., Cortés, J. y Valverde, A. (1967). Ensayo histórico del Partido de Olavarría. Olavarría: Municipalidad de Olavarría.

Barbará, F. (1856). Usos y costumbres de los indios pampas. Buenos Aires: Imp. de J.A. Bernheim

Barbuto, L. (2014). Iniciativas criollas y territorios indigenas: los proyectos de tierras para los indios amigos de Azul y Tapalqué (1860-1870). XI Congreso Argentino de Antropología Social. Rosario.

Barcos, M. F. (2017). Tratos, batallas y malones. El accionar indígena en la Frontera Sur durante el Sitio a la ciudad de Buenos Aires. Corpus, 7(1), 1-30 (enero-junio).

Barcos, M. F. y Lanteri, S. (2017). Entre la antigua ocupación y la modernización liberal. Una primera mirada de conjunto sobre pueblos, ejidos y campos criollos e indígenas en la frontera sur de Buenos Aires (siglo XIX), Ms. Estudios del hábitat Vol. 16 (1) 
Bechis, M. (1989). Los lideratos políticos en el área arauco-pampeana en el siglo XIX: ¿Autoridad o poder? I Congreso de Etnohistoria, Buenos Aires.

Bechis, M. (1998). Fuerzas indígenas en la política criolla del siglo XIX. En N. Goldman y R. Salvatore (Comp.), Caudillismos Rioplatenses. Nuevas miradas a un viejo problema (pp. 293-317). Buenos Aires: Eudeba.

Belloni, C. (2015). La política indígena del Estado de Buenos Aires en la frontera sur. Azul y Tapalqué entre 1852 y 1862. En V. Pedrotta y S. Lanteri, (Dirs.), La frontera sur de Buenos Aires en la larga duración. Una perspectiva multidisciplinar (pp. 133-167). La Plata: AHPBA.

Capdevila, R. (1963). Tapalqué en la historia. Desde sus origenes hasta la época actual. Azul: Edición del autor, 2 Tomos.

Cornell, J. (1995) [1864]. De los hechos de armas con los indios. Fuentes para el estudio de la historia de la provincia de Buenos Aires, No 1. Tandil y Luján: IEHS-UNLu.

Crivelli, E. (2004). Pactando con el enemigo: la doble frontera de Buenos Aires con las tribus hostiles en el periodo colonial. En M. S. Cipolleti (Comp.) Los mundos de abajo y los mundos de arriba. Individuo y sociedad en las tierras bajas, en los Andes y más allá (pp. 313-356). Quito: ABYA YALA.

Cutrera, M. L. (2013). Que todavía no se ha acabado esto: Sobre el fin del Negocio Pacífico de Indios después de Caseros. Anuario del Instituto de Historia Argentina, 13, 1-20 Disponible en: http:// www.memoria.fahce.unlp.edu.ar/art_revistas/pr.6148/pr.6148.pdf

de Jong, I. (2007). Políticas indígenas y estatales en Pampa y Patagonia (1850-1880). Habitus, 5(2), 301-331.

de Jong, I. (2015). El acceso a la tierra entre los indios amigos de la frontera bonaerense (1850-1880). Revista de Ciencias Sociales, segunda época, año 7, 27, 87-117. Disponible en http://www.unq.edu.ar/catalogo/357revista-de-cien cias-sociales-n-27.php

de Jong, I. (2016). Prácticas de la diplomacia fronteriza en las Pampas, siglo XIX. Habitus, 14(2), 175-197.

de Jong, I., Lanteri, S., Pedrotta, V. y Ratto, S. (2009). Políticas oficiales y territorialidad indígena en la frontera sur bonaerense durante el siglo XIX. El caso de Villa Fidelidad (1856-2009). CD de las Jornadas de Estudios Indigenas $y$ Coloniales. CEIC: UNJu, Jujuy.

Del Valle, A. (1926). Recordando al pasado. Campañas por la civilización. Tomo I.

Durán, J. G. (2002). En los toldos de Catriel y Railef. La obra misionera del Padre Jorge María Salvaire en Azuly Bragado, 1874-1876. Buenos Aires: Facultad de Teología-UCA.

González, M. A. (1967). Catrie Mapu-Monografía sobre los Catriel. Olavarría: Museo Etnográfico Municipal Dámaso Arce.

Hux, M. (1993). Caciques Puelches, Pampas y Serranos. Buenos Aires: Marymar.

Langer, E. (2003). La frontera oriental de los Andes y las fronteras en América Latina. Un análisis comparativo. Siglos XIX y XX. En R. Mandrini y C.Paz, (Comp.), Las fronteras hispanocriollas del mundo indigena latinoamericano en los siglos XVIII-XIX. Un estudio comparativo (pp. 33-62). Neuquén, Bahía Blanca, Tandil: UNCo, UNSur, UNCPBA.

Lanteri, S. (2011). Un vecindario federal. La construcción del orden rosista en la frontera sur de Buenos Aires (Azuly Tapalqué). Córdoba: Centro de Estudios Históricos "Prof. Carlos S. A. Segreti”-CONICET.

Lanteri, S. (2017). De la inmensidad de la llanura al arrabal de un pueblo. Villa Fidelidad, los premios y donaciones de tierras en la frontera sur bonaerense durante el proceso de revisión liberal. Pasado Abierto, 3(6), 177-200.

Lanteri, S. y Pedrotta, V. (2007). Mirando de a dos: espacio y territorio en la frontera sur bonaerense durante el siglo XIX, un enfoque interdisciplinario. CD del II Encuentro de Investigadores. Fuentes y Problemas de la Investigación Histórica Regional. Santa Rosa: UNLaPam.

Lanteri, S. y Pedrotta, V. (2012). Mojones de piedra y sangre en la pampa bonaerense. Estado, sociedad y territorio en la frontera sur durante la segunda mitad del siglo XIX. Revista Tefros. 10(1,2), 1-25.

Lanteri, S. y Pedrotta, V. (2017). Villa Fidelidad y las tierras indígenas en la frontera sur de Buenos Aires, 2da mitad del siglo XIX. Mar del Plata: XVI Jornadas Interescuelas/Departamentos de Historia. 
Lanteri, S., Ratto, S., de Jong, I., y Pedrotta, V. (2011). Territorialidad indígena y políticas oficiales de colonización. Los casos de Azul y Tapalqué en la frontera sur bonaerense (siglo XIX). AntíTeses, 8, http://www.uel.br/revis tas/uel/index.php/antiteses

Levaggi, A. (2000). Paz en la Frontera. Historia de las relaciones diplomáticas con las comunidades indígenas en la Argentina. (Siglos XVI-XIX). Buenos Aires: UMSA.

Literas, L. (2015). De donaciones, arrendamientos y compras. Acceso y uso de la tierra de los indios amigos (la tribu de Rondeau, segunda mitad siglo XIX). Publicar, 13(18), 59-84.

Literas, L. (2016). Armas, parentesco y tierra en las fronteras. La tribu de Rondeau y los orígenes de 25 de Mayo (1834-1880). En I. de Jong (Comp.), Diplomacia, malones y cautivos en la frontera sur, siglo XIX. Miradas desde la Antropología Histórica (pp. 263-327). Buenos Aires: SAA.

Literas, L. y Barbuto, L. (2015). El acceso a la tierra de los indios amigos. Una comparación preliminar de las tribus de Catriel y Rondeau (Buenos Aires, segunda mitad del siglo XIX). TEFROS, 13(2), 149-170.

Lobos, O. (2015). Juan Calfucurá. Correspondencia 1854-1873. Buenos Aires: Colihue.

Martinelli, M. L. y M. Acosta (2016). La cuestión de la tierra pública en la frontera sur bonaerense en las décadas de 1860 y 1870 : tensiones, negociaciones y agencias de indios, criollos e inmigrantes. El caso de Bahía Blanca. Tefros, $14(2), 87-116$.

Míguez, E. (2003). Guerra y Orden social en los orígenes de la Nación Argentina, 1810 -1880. Anuario IEHS, 18, 17-38.

Míguez, E. (2010). La frontera sur de Buenos Aires y la consolidación del Estado liberal, 1852-1880. En B. Bragoni, y E. Míguez (Coords.), Un nuevo orden político. Provincias y Estado Nacional, 1852-1880 (pp. 79-97). Buenos Aires: Biblos.

Muzlera, J. (s/f). Tierras Públicas. Recopilación de leyes, decretos y resoluciones de la provincia de Buenos Aires sobre tierras públicas desde 1810 a 1895, Tomos I-III. La Plata: Isidro Solá Sanz.

Pavez, J. (Comp) (2008). Cartas Mapuche Siglo XIX. Santiago de Chile: Ocho Libros/CoLibris.

Pedrotta, V. (2015). Recursos, espacio y territorio en las sierras del Cayrú (siglos XVI-XIX, región pampeana argentina). En V. Pedrotta, y S. Lanteri (Dirs.), La frontera sur de Buenos Aires en la larga duración. Una perspectiva multidisciplinar (pp. 53-94). La Plata: AHPBA.

Pedrotta, V., Lanteri, S. y Duguine, L. (2012). En busca de la tierra prometida. Modelos de colonización estatal en la frontera sur bonaerense durante el siglo XIX. Nuevo Mundo Mundos Nuevos [En línea] Debates. París. EHESS. Puesto en línea el 05 octubre 2012, consultado el 08 octubre. URL: http://nuevomundo.revues.org/64168, DOI: $10.4000 /$ nuevomundo.64168.

Pedrotta, V. y Lanteri, S. (2016). Tierras y nuevas territorialidades indigenas en la frontera sur de Buenos Aires. Argentina. Historia y Arqueologia de Villa Fidelidad (siglos XIX-XXI). II CIPIAL.Santa Rosa: UNLaPam.

Pérez Zavala, G. (2005). Oralidad y escritura. Los tratados de paz entre el Estado argentino y las tribus ranqueles. Tefros, 3(1), 1-30.

Pinto Rodríguez, J. (1996). Integración y desintegración de un espacio fronterizo. La Araucanía y las Pampas, 1550-1900. En J. Pinto Rodríguez (ed), Araucania y Pampas. Un mundo fronterizo en América del Sur (pp. 11-46). Temuco: Universidad de la Frontera.

Ratto, S. (2003). Una experiencia fronteriza exitosa: el 'negocio pacífico' de indios en la provincia de Buenos Aires (1829-1852). Revista de Indias, LXIII, 191-222.

Ratto, S. (2006). Ni unitarios ni rosistas. Estrategias políticas interétnicas en Buenos Aires (1852-1857). Estudos de História, 13 (2), 67-101.

Ratto, S. (2012). Haremos lo posible para asegurar y tranquilizar la frontera. La defensa de la frontera bonaerense durante la década de 1850. En J. C. Garavaglia, J. Pro Ruiz y E. Zimmerman (Eds.), Las fuerzas de guerra en la construcción del Estado en América Latina, siglo XIX (pp. 357-380). Rosario: Prohistoria, SBLA.

Ratto. S. (2015). Redes politicas en la frontera bonaerense (1836-1873). Crónica de un final anunciado. Bernal: UNQ.

Ronco, B. (1930). Azul. Revista de ciencias y letras. Año 1, 3. 
Ronco, B. (1946). El General Manuel de Escalada y la Fundación de Villa Fidelidad. En Cuadernos del Azul, 9-22. Azul: Biblioteca Popular.

Roulet, F. (2004). Con la pluma y la palabra. El lado oscuro de las negociaciones de paz entre españoles e indígenas. Revista de Indias, LXIV, 231, 313-348.

Sarramone, A. (1993). Catriel y los indios pampas de Buenos Aires. Azul: Biblos.

Vezub, J. (2011). Llanquitruz y la "máquina de guerra" mapuche-tehuelche: continuidades y rupturas en la geopolítica indígena patagónica (1850-1880). AntíTeses, 4(8), 645-674.

\section{Notas}

1 CONICET, PIP 0304"Arqueología e historia de la frontera sur de Buenos Aires durante la segunda mitad del siglo XIX: campos, ejidos y territorio indígena desde una mirada interdisciplinar" y ANPCyT, PICT 0219 "La construcción del territorio en la frontera sur de Buenos Aires en perspectiva arqueológica e histórica. Campos, ejidos y tierras indígenas en la 2da mitad del S. XIX"

2 Ver, entre otros, los dossiers sobre diversas temáticas publicadas en: http://historiapolitica.com/dossiers

3 Durante el lapso 1829-1852, por ejemplo, se han contabilizado 15 años de guerra contra 8 de relativa paz (Míguez, 2003, p. 18)

4 Por "tribus" no deben entenderse unidades étnicas ni políticas fijas y discretas -como se las definió desde perspectivas esencialistas-; por el contrario, se emplea este término para denominar agrupaciones culturalmente heterogéneas, producto de alianzas dinámicas, a veces coyunturales, bajo un liderazgo político estructuralmente segmental (ver Bechis 1989; de Jong, 2007). Asimismo, parcialidad es un concepto que operativamente refiere a una agrupación de individuos mucho menor que se reconoce al mando de un líder, que puede ser de diferente jerarquía (cacique, caciquillo, capitanejo, etc.)

5 Ronco, 1930, “Cuentas de proveedores” en Azul. Revista de ciencias y letras, Año 1, №3, pp. 134-151 y Documentos del Archivo Histórico de Azul, Doc. 1 de 1845, en Sarramone (1993, p. 139). La composición detallada de las raciones comestibles para la tribu de Maicá es la siguiente. En 1846: aguardiente, vino, yerba, azúcar, pasas, arroz, sal, tabaco, pliegos de papel, por un total de 570 pesos. En 1848: yerba, azúcar, pasas, pañuelos, mantas paño punzó, tabaco y botellas de aguardiente por un total de 546 pesos.

6 La participación indígena en conflictos faccionales criollos fue común desde principios de la centuria (ver Bechis, 1998)

7 Además de prestar su servicio armado, varios de ellos participaron de las elecciones regulares para representantes provinciales durante el rosismo. Véase Lanteri, 2011 (cap. 3, especialmente pp. 220-223)

8 Carta de Olmos al mayor Eugenio Bustos, 8 de febrero de 1853 (en Barcos, 2017, p. 10; énfasis nuestro)

9 Carta del coronel Julián Martínez a Bartolomé Mitre, Fuerte Azul, 11 de mayo de 1855 en Archivo Mitre, Tomo XV, pp. 106-107 (énfasis nuestro)

10 Carta del Ministro de Guerra y Marina Bartolomé Mitre al gobernador Pastor Obligado del 2 de junio de 1855 (transcripta en Arena, Cortés \& Valverde, 1967, pp. 251-259). También Diario La Tribuna del 19-05-1855, 31-05-1855 y 09-06-1855 en Sarramone, 1993, p. 167; Hux, 1993, p. 130; Del Valle, 1926 y Ronco, 1930).

11 Parte del combate publicado en el Diario El Nacional el 2-11-1855 (transcripto en Capdevila, 1963, pp. 155-157; Arena, Cortés \& Valverde, 1967, pp. 209-212; énfasis nuestro)

12 Hijo del cacique Juan Catriel “el viejo” a quien sucedió tras su muerte a partir de 1848, también llamado Juan "segundo" Catriel.

13 Sin embargo, investigaciones recientes proponen una lectura distinta, al destacar la activa y autónoma participación de estos grupos en los conflictos desatados por el sitio de Lagos (diciembre 1852-julio de 1853), con notables costos económicos para el sur provincial. Véase Barcos (2017).

14 Ministerio de Gobierno al Juez de Paz de Tapalqué, 5 de abril de 1854 (transcripto en Capdevila, 1963, pp. 142-143)

15 La cuestión territorial dentro de los acuerdos entablados entre Juan Catriel “el Viejo”, Juan Manuel Cachul y Juan Manuel de Rosas ha sido abordada en trabajos previos, donde se ha planteado que muy probablemente se trató de un asentamiento que fue convenido verbalmente, como era costumbre de Rosas. Son coincidentes al respecto tanto testimonios contemporáneos (Barbará, 1856, p. 59) como investigaciones posteriores (Arena, Cortés \& Valverde, 1967; Hux, 1993; Durán, 2002).

16 Resolución del Departamento de Gobierno del 2 de marzo de 1855 firmada por Pastor Obligado e Ireneo Portela (transcripta en Capdevila, 1963, pp. 127-128; énfasis nuestro). Ver también este decreto en Muzlera (s/f, 151-152) y más detalles en Barcos y Lanteri (2017)

17 Decreto del Ministro de Guerra y Marina de 1855 (transcripto parcialmente en Capdevila, 1963, pp. 128-129). 
18 Carta de Julián Martínez a Bartolomé Mitre del 11 de mayo de 1855 (Archivo Mitre, To XV, pp. 107-108)

19 Más detalles sobre estos sucesos en Capdevila (1963) y Arena, Cortés \& Valverde (1967).

20 Carta de Bartolomé Mitre al gobernador Pastor Obligado del 4 de junio de 1855 (transcripta en Del Valle, 1926, pp. 23-27; énfasis nuestro)

21 En la frontera sur, los ejemplos más notorios son las ya mencionadas batallas de Sierra Chica y San Jacinto o Tapalqué; en ambas, las fuerzas indígenas confederadas derrotaron cabalmente al Ejército de Operaciones del Sud.

22 Carta del gobernador Pastor Obligado al ministro de guerra y marina Bartolomé Mitre, 21 de febrero de 1856 (Archivo Mitre, To XV, pp. 80-81). Sobre la renuncia de Hornos, ver además la carta del gobernador Pastor Obligado a Bartolomé Mitre del 29 de febrero de 1856 (Archivo Mitre, To XV, pp. 83-84).

23 Carta del gobernador Pastor Obligado al cacique Juan Catriel, 22 de marzo de 1856 (Archivo Mitre, To XV, pp. 86-88; énfasis nuestro)

24 Ver además en este sentido la misiva de Mitre a Escalada, 22 de enero de 1857 (AGN, X, 19-5-4, en Lobos, 2015, pp. $159-160$

25 Carta de Juan Catriel a Francisco Iturra, ca. mayo/junio de 1856 (transcripta en Levaggi, 2000, p. 294; énfasis nuestro).

26 Carta de Francisco Iturra a Catriel, 13 de agosto de 1856 y carta de Juan Susviela a Catriel, 13 agosto de 1856 (AGN, $\mathrm{X}, 19-4-6)$. La comisión que efectivamente fue a las tolderías, al mando del Capitán de Caballería José Quintana, estaba integrada por el teniente de Guardias Nacionales "Don Cruz" y Manuel Iturra, hijo de Francisco Iturra, entre otros (Carta de Juan Catriel al comandante Juan Susviela, 8 de septiembre de 1856, copia, AGN, X, 19-4-6; también transcripta en Pavez, 2008, pp. 285-286).

27 Instrucciones de Juan Susviela al Capitán de Caballería José Quintana, agosto de 1856 (AGN, X, 19-4-6; énfasis nuestro)

28 Carta de Juan Susviela a Catriel, 24 de agosto de 1856 (AGN, X, 19-4-6; énfasis nuestro)

29 Carta de Juan Catriel al comandante Juan Susviela, 8 de septiembre de 1856 (AGN, X, 19-7-3; también transcripta en Pavez, 2008, pp. 285-286; énfasis nuestro).

30 Sobre la diplomacia fronteriza para lugares y/o períodos diferentes puede consultarse, entre otros, Pinto Rodríguez (1996), Pérez Zabala (2004), Roulet (2005), Vezub (2011) y de Jong (2007, 2016)

31 AGN, X, Estado de Buenos Aires, 28-10-7. El tratado está transcripto íntegramente en Levaggi (2000, pp. 298-300).

32 AGN, X, Estado de Buenos Aires, 28-10-7 (énfasis nuestro).

33 Según se aclara en dicho artículo, los fondos provenían de una gran suscripción que se había hecho entre los vecinos de Buenos Aires y la campaña para lograr la liberación de las cautivas y promover la paz (AGN, X, Estado de Buenos Aires, 28-10-7; énfasis nuestro).

34 AGN, X, Estado de Buenos Aires, 28-10-7

35 Carta de Bartolomé Mitre, 15 de noviembre de 1856 (en Levaggi, 2000, p. 302)

36 Carta de Juan Catriel y Juan Manuel Cachul a Manuel Escalada, 23 de diciembre de 1856 (transcripta en Pavez, 2008, pp. 310-311; énfasis nuestro).

37 Sobre este tema puede consultarse Pedrotta (2015)

38 Carta de Manuel Escalada al coronel Alejandro Romero, 30 de diciembre de 1856 (transcripta en Levaggi, 2000, pp. 303-304; énfasis nuestro).

39 Por ejemplo, el "Plano del Partido Arroyo Azul construido por el Sgto. Mayor Don Juan Cornell, octubre 1859”, el Duplicado de Diligencia de Mensura de Azul, No101, 1863, el "Plano de las Suertes de Estancia del Azul” de J. Dillón, 1872, Duplicado de Mensura de Azul No 159 y un croquis hecho por el general Ignacio Rivas en 1863, entre otras fuentes cartográficas que fueron analizadas en Lanteri \& Pedrotta (2012) y Pedrotta, Lanteri \& Duguine (2012).

40 Los pormenores de este proceso de compra están siendo analizados para determinar el origen de los fondos y las condiciones del acuerdo con la Corporación Municipal, entre otras cuestiones de interés.

41 Plano de Villa Fidelidad, 1856, Museo Etnográfico y Archivo Histórico "Enrique Squirru” de Azul.

42 Más detalles sobre este tema y los derechos de propiedad en Lanteri (2017).

43 Plano de Villa Fidelidad (1856) y Libro Nº , Actas de Sesiones Municipales (1856), Museo Etnográfico y Archivo Histórico "Enrique Squirru" de Azul. Se indica entre paréntesis el número de solar que corresponde a cada individuo.

44 Agradecemos a Silvia Ratto por esta fuente.

45 Tema que estamos analizando en un trabajo en curso.

46 Carta de Benito Villar a B. Mitre, Patagones, 14 de abril de 1857 (en Levaggi, 2000, p. 288; énfasis nuestro)

47 Aunque con la forma de "donación condicionada" al poblamiento y cumplimiento de una serie de disposiciones por parte de los indios receptores (ver Lanteri, 2017). 